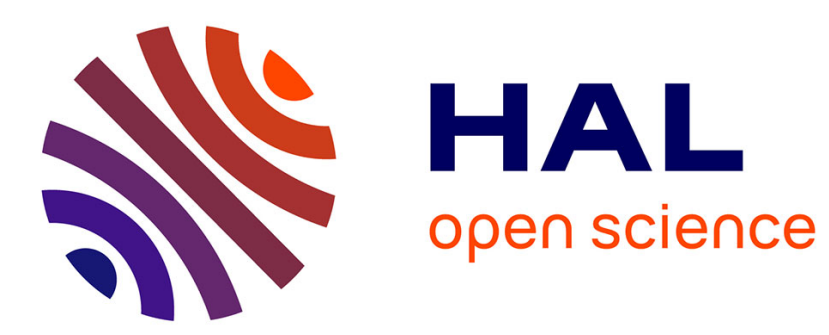

\title{
A transgenic mouse model engineered to investigate human brain-derived neurotrophic factor in vivo
}

Fabrice Guillemot, Italina Cerutti, Charles Auffray, Marie-Dominique

Devignes

\section{- To cite this version:}

Fabrice Guillemot, Italina Cerutti, Charles Auffray, Marie-Dominique Devignes. A transgenic mouse model engineered to investigate human brain-derived neurotrophic factor in vivo. Transgenic Research, 2006, 10.1007/s11248-006-9060-0 . inria-00103858

\section{HAL Id: inria-00103858 \\ https://hal.inria.fr/inria-00103858}

Submitted on 22 Nov 2006

HAL is a multi-disciplinary open access archive for the deposit and dissemination of scientific research documents, whether they are published or not. The documents may come from teaching and research institutions in France or abroad, or from public or private research centers.
L'archive ouverte pluridisciplinaire HAL, est destinée au dépôt et à la diffusion de documents scientifiques de niveau recherche, publiés ou non, émanant des établissements d'enseignement et de recherche français ou étrangers, des laboratoires publics ou privés. 


\section{Editorial Manager(tm) for Transgenic Research \\ Manuscript Draft}

Manuscript Number: TRAG342R1

Title: A transgenic mouse model engineered to investigate human brain-derived neurotrophic factor in vivo

Article Type: Original research papers

Section/Category:

Keywords: BDNF; neurotrophic factor; YAC; transgene; expression; reporter

Corresponding Author: Dr Charles Auffray, Ph.D.

Corresponding Author's Institution:

First Author: Fabrice Guillemot, Ph.D.

Order of Authors: Fabrice Guillemot, Ph.D.; Italina Cerruti; Charles Auffray, PhD; Marie-Dominique Devignes, Ph.D.

Manuscript Region of Origin:

Abstract: Brain-derived neurotrophic factor (BDNF) is an attractive component for the treatment of various neurodegenerative diseases such as Alzheimer's or Parkinson's disease. Innovative non invasive therapeutic approaches involve appropriate pharmacological induction of endogenous BDNF synthesis in brain. A transgenic mouse model has been established to study human BDNF gene expression and permit the screening of compounds capable of stimulating its activity. A 145-kb yeast artificial chromosome carrying the human BDNF gene has been engineered to produce the transgene which contains the extended BDNF promoter and 3' flanking regions and has integrated the enhanced green fluorescent protein (E-GFP) coding sequence in place of the BDNF coding exon. Five transgenic lines have been obtained through microinjection of the YAC into fertilized mouse oocytes. From the three lines expressing the transgene, one displays the specific pattern of BDNF expression. Faithful tissue-restricted transcription of BDNF 5' exons 
and localization of the fluorescent reporter gene product in the expected brain subregions are reported. This line constitutes an exploitable system for investigating human BDNF gene regulation in vivo. 

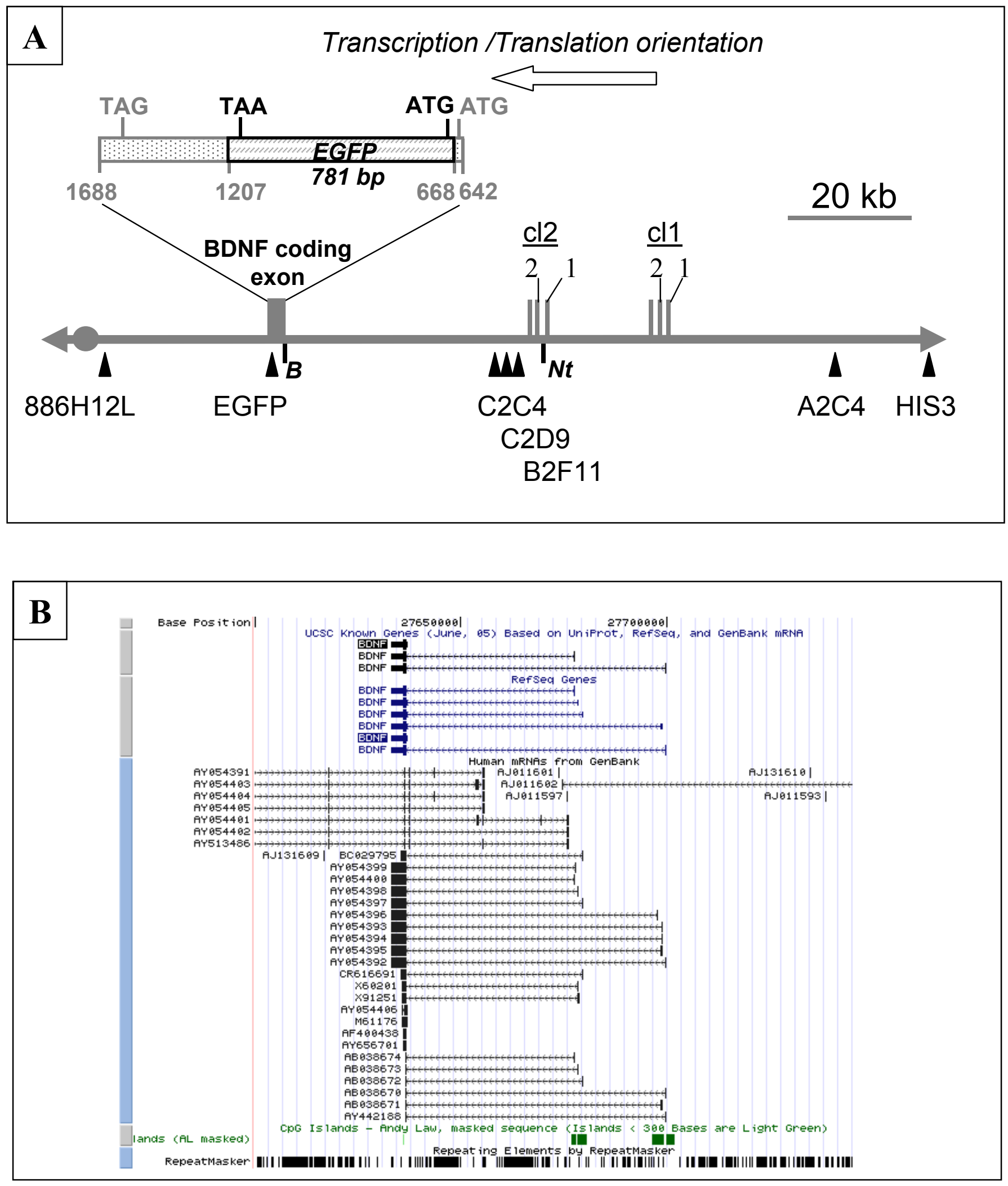
A)
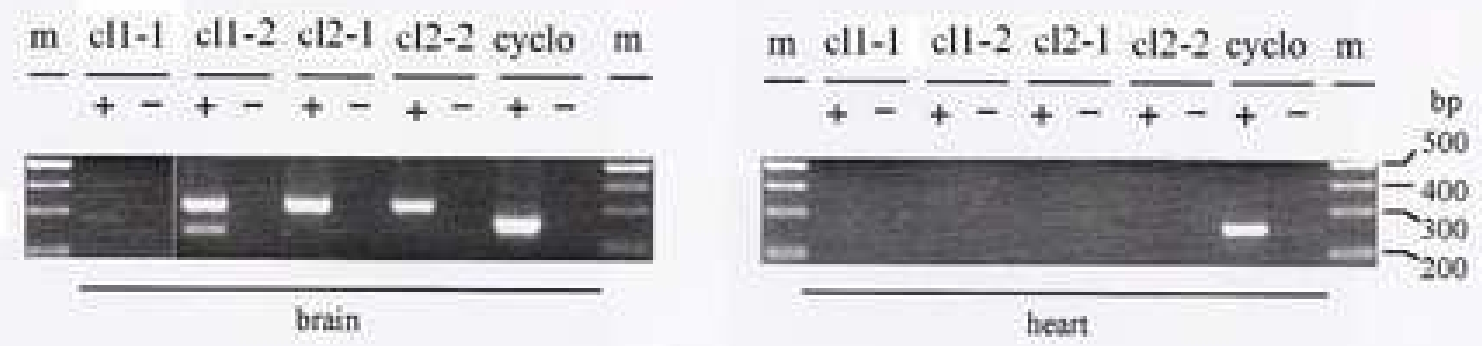

$$
\frac{\mathrm{m}}{\mathrm{cll}-1}+\frac{\mathrm{cll}-2}{+-} \frac{\mathrm{cl} 2-1}{+-} \frac{\mathrm{cl} 2-2}{+-}+\frac{\text { cyclo } \mathrm{m}}{+-}
$$

m cll-1 cll-2 c12-1 cl2-2 cyclo $m$

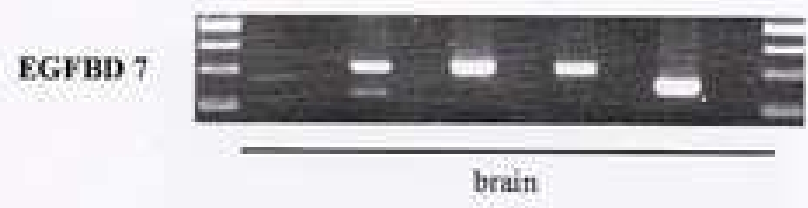

$$
\frac{\mathrm{m}}{\mathrm{cll}-1} \mathrm{cll}-2 \mathrm{cl} 2-\mathrm{I} \mathrm{cl} 2-2 \text { cyclo } \mathrm{m}
$$

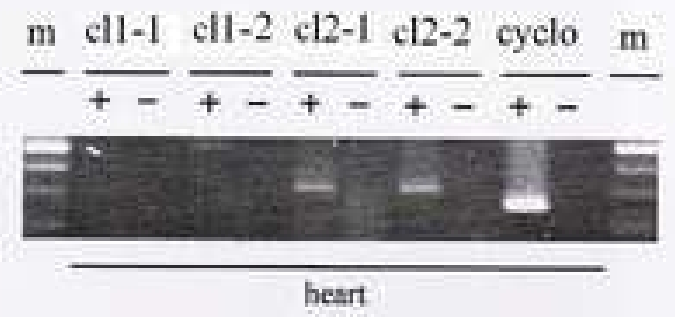

B)
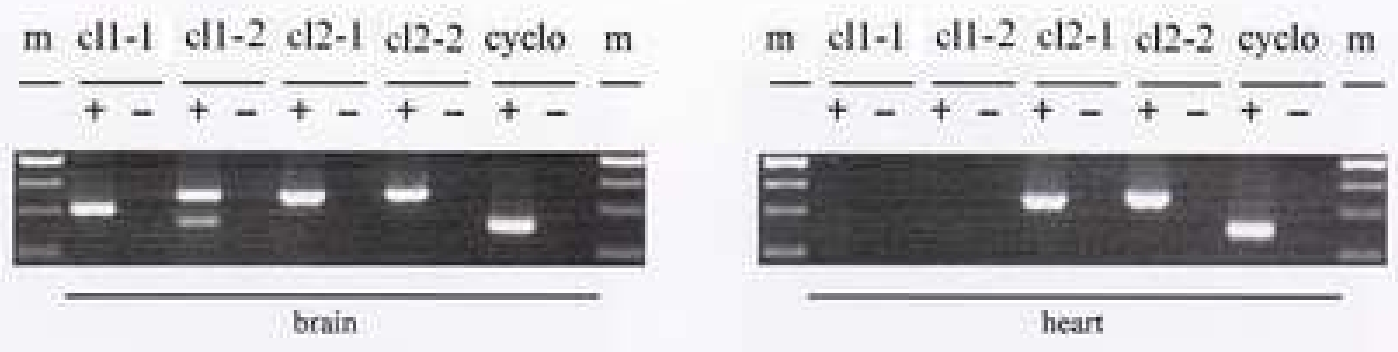
colour figure
Click here to download high resolution image

A)

non-tg
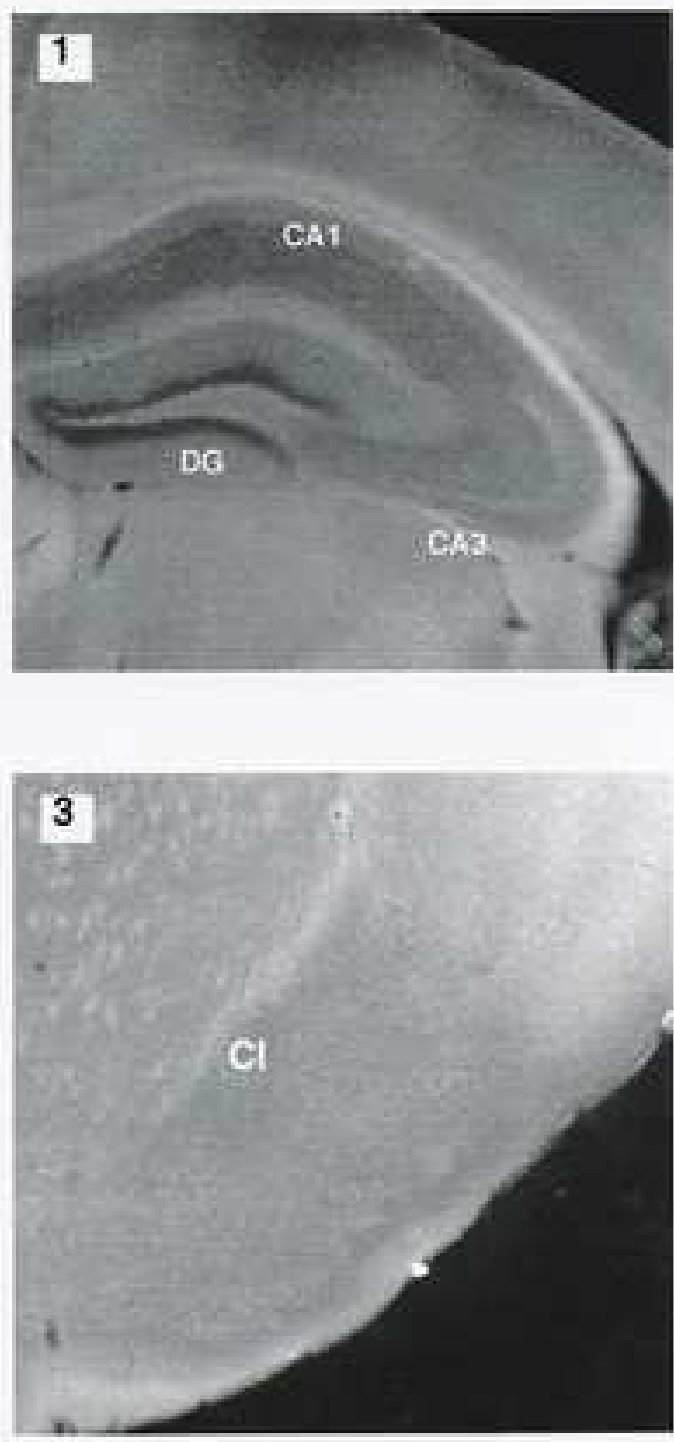

B)

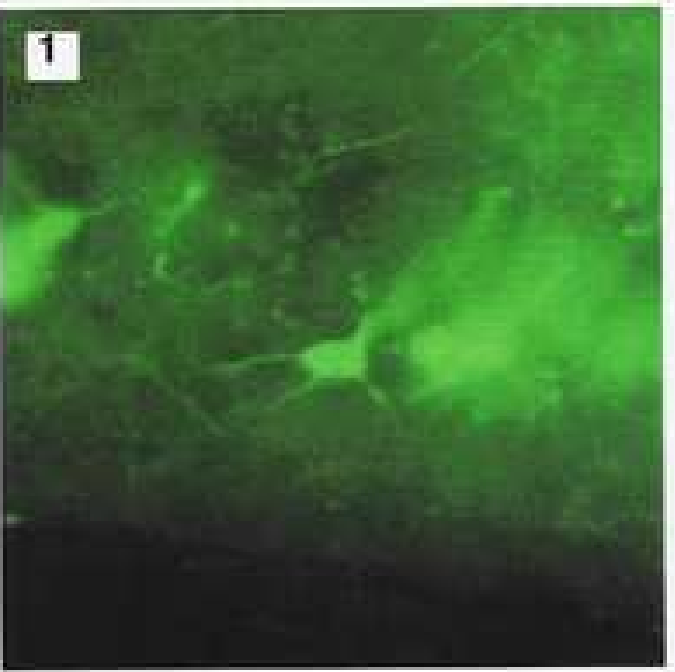

$\operatorname{tg}$
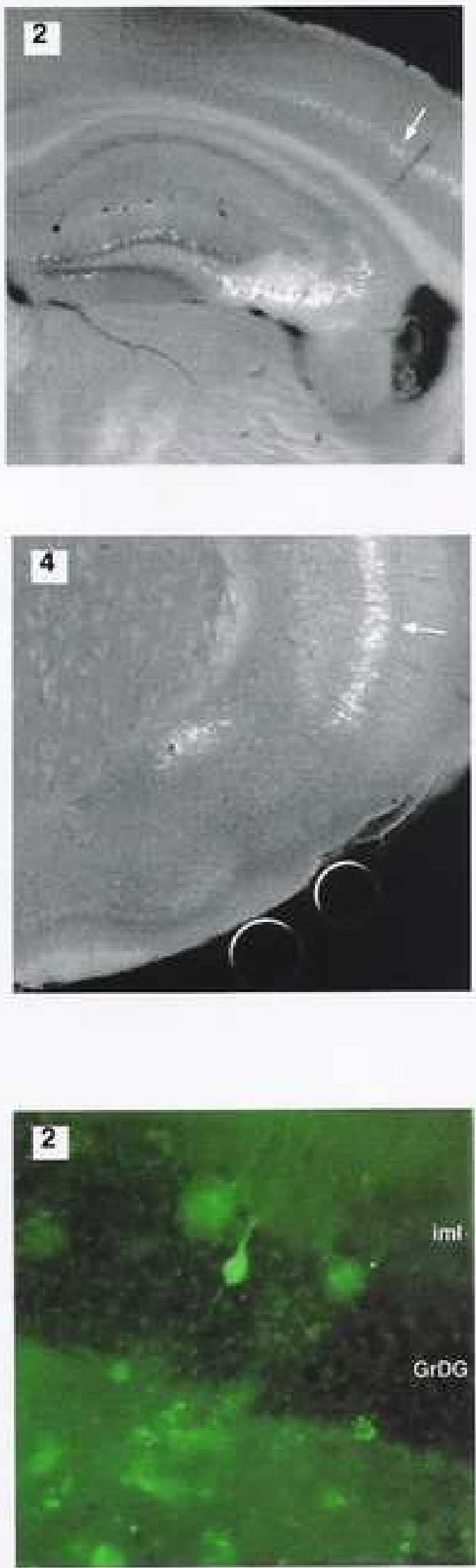


\section{A transgenic mouse model engineered to investigate human brain-derived neurotrophic factor in vivo}

Fabrice Guillemot ${ }^{1}$, Italina Cerutti ${ }^{2}$, Charles Auffray $^{1}$ and Marie-Dominique Devignes ${ }^{1,3}$

Author affiliation: 1-Genexpress, Génomique Fonctionnelle et Biologie Systémique pour la Santé, CNRS et Université Pierre et Marie Curie Paris VI, LGN, UMR 7091, 94801 Villejuif, France ; 2Service d'Expérimentation Animale et de Transgenèse, SEAT, CNRS UPS 44, 94801 Villejuif, France ; 3Laboratoire Lorrain en Informatique et ses Applications, LORIA, CNRS UMR 7503, 54500 Vandoeuvre-les Nancy, France.

Corresponding author: Charles Auffray, Genexpress, Génomique Fonctionnelle et Biologie Systémique pour la Santé, CNRS et Université Pierre et Marie Curie Paris VI, LGN, UMR 7091, 7 rue Guy Moquet, BP8, 94801 Villejuif cedex, France ; Tel : +33-1-49-58-34-97 ; Fax : +33-1-49-58-35-09 ; E-mail : charles.auffray@vjf.cnrs.fr.

Abbreviations footnote : BDNF, brain-derived neurotrophic factor; YAC, yeast artificial chromosome, E-GFP, enhanced green fluorescent protein; STS, sequence-tagged site; kb, kilobase; nt, nucleotide; PCR, polymerase chain reaction.

Keywords: BDNF, neurotrophic factor, YAC, transgene, expression, reporter 


\begin{abstract}
Brain-derived neurotrophic factor (BDNF) is an attractive component for the treatment of various neurodegenerative diseases such as Alzheimer's or Parkinson's disease. Innovative non invasive therapeutic approaches involve appropriate pharmacological induction of endogenous BDNF synthesis in brain. A transgenic mouse model has been established to study human BDNF gene expression and permit the screening of compounds capable of stimulating its activity. A 145-kb yeast artificial chromosome carrying the human $B D N F$ gene has been engineered to produce the transgene which contains the extended BDNF promoter and 3' flanking regions and has integrated the enhanced green fluorescent protein (E-GFP) coding sequence in place of the BDNF coding exon. Five transgenic lines have been obtained through microinjection of the YAC into fertilized mouse oocytes. From the three lines expressing the transgene, one displays the specific pattern of BDNF expression. Faithful tissue-restricted transcription of BDNF 5' exons and localization of the fluorescent reporter gene product in the expected brain subregions are reported. This line constitutes an exploitable system for investigating human BDNF gene regulation in vivo.
\end{abstract}




\section{INTRODUCTION}

Brain-derived neurotrophic factor (BDNF) is a member of the neurotrophin family which groups together small basic proteic factors, structurally and functionally related to nerve growth factor (NGF) (LeviMontalcini, 1987, Hallbook et al, 1998). These proteins display various trophic activities on specific neuronal populations during development (Snider, 1994) and in adulthood (Davies et al, 1995, Connor et al, 1998). Several features of BDNF have made this factor a very attractive candidate for therapeutic strategies against common neurodegenerative diseases such as Alzheimer's disease, Parkinson's disease or amyotrophic lateral sclerosis (Connor et al, 1998, Yuen et al, 1996) and more recently Huntignton's disease (Ferrer et al, 2000).

In Alzheimer's disease (AD), the decrease in BDNF mRNA level observed in the hippocampus of AD patients (Phillips et al, 1991, Murray et al, 1994) may contribute to the hallmark of this pathology : progressive degeneration of the basal forebrain cholinergic neurons. Several in vivo experiments have shown that BDNF is required for the survival of these septal neurons (Nonomura et al, 1995, Eide et al, 1993). In addition to trophic activities, numerous recent studies have revealed BDNF functions concerning neuronal activity and plasticity (McAllister et al, 1999), reviewed in (Mattson et al, 2004). BDNF has been shown to have a central role in the formation of hippocampal long-term potentiation, in an experimental study of synaptic transmission related to learning and memory formation (Patterson et al, 1996, Ma et al, 1998). Thus the impairment of $B D N F$ gene expression in AD patients' hippocampus could also directly contribute to the cognitive deterioration characteristic of AD. Furthermore, BDNF has been shown to stimulate glycolysis and glucose uptake in cortical cell cultures (Knusel et al, 1996). Thus this factor could be used as treatment for another $A D$ feature : alteration of energy metabolism in brain cortical areas.

The critical goal a pharmacological treatment of these diseases should reach is to ensure a constant level of the neurotrophic molecule close to the sensitive neurons. Several experimental modes of administration have been described for BDNF: (i) systemic injection of a molecular reformulated BDNF (Wu et al, 1999), (ii) infection with engineered adenoviral vectors encoding this factor (Gimenez y Ribotta et al, 1997), (iii) graft of cells modified by BDNF-coding retroviral vectors (Menei et al, 1998, Martinez- 
Serrano et al, 1996, Levivier et al, 1995, Girard et al, 2005). Alternatively, it may be envisioned to stimulate by appropriate drugs the production of endogenous BDNF in cells or tissues close to the site of action. This strategy has already been proposed for NGF in the case of other neurodegenerative diseases (Saporito et al, 1993, Carswell, 1993, Semkova et al, 1999). In this perspective, the generation of an animal model to study in vivo the regulation of the human BDNF gene can be considered as a valuable contribution towards finding specific compounds displaying novel therapeutic properties.

Primary descriptions of BDNF gene organization have been reported in rodents (Timmusk et al, 1993, Bishop et al, 1994, Hayes et al, 1997) and in human (Rosier et al, 1994), and our unpublished results). Increasing availability of genome and transcript sequences (for example on the Genome Browser web site http://genome.ucsc.edu/cgi-bin/hgGateway?) have now provided more precise pictures of BDNF gene organisation in several species. The protein is entirely encoded by a unique exon with two polyadenylation signals at the 3' untranslated end. Multiple 5' non coding exons are alternatively spliced to the coding exon. Alternative donor sites exist in the 3' region of several exons, further increasing the potential diversity of $B D N F$ transcripts. In brief, two main clusters of 5 ' exons are detected upstream of the coding exon at distances ranging from $26 \mathrm{~kb}$ in rat to $41 \mathrm{~kb}$ in human. Isolated additional exons are also occasionnally described between the second cluster and the coding exon but they are poorly documented and have not been taken into account in this study. The two 5' clusters (about 2 to $2.5 \mathrm{~kb}$ each) are separated by a $15-$ to $17-\mathrm{kb}$ intron. Each cluster contains three 5' exons (100 to 700-nt long). For sake of clarity the BDNF 5' exons will be numbered here according to their position in the cluster preceded by cl1 or $\mathrm{cl} 2$ for the first or the second cluster respectively (Figure 1). In this work, the four 5 ' exons mainly used in previous studies (Timmusk et al, 1995) have been selected to study BDNF gene expression. These four 5' non coding exons, initially noted I, II, III and IV in rat (Timmusk et al, 1993), correspond here to exons cl1-1, cl1-2, cl2-1 and cl2-2, described for the human BDNF gene in RefSeq entries NM_170731, NM_170732, NM_170733, and NM_001709 respectively. Corresponding exons are described in rat GenBank entries S76758, S76759/M67175, S76760 and S76799, as well as in mouse GenBank entries AY057908, AY057910/AY057911, AY057913 and AY057914.

Expression of the murine BDNF gene has been mainly detected in the central nervous system, mostly in hippocampus and claustrum (Hofer et al, 1990, Yan et al, 1997, Conner et al, 1997). In contrast 
with the precise descriptions existing for BDNF mRNA distribution in rat brain, only limited information is available for human brain (Phillips et al, 1991, Murray et al, 1994); data concern mostly the hippocampus formation and are consistent with reports in rodents.

Transgenic models have been constructed to study the rat BDNF gene (Timmusk et al, 1995). Analysis of the transgenic lines has confirmed the differential use of the four promoter regions of the murine gene, depending on tissues or on various exogenous stimulations. However, the portions of the $B D N F$ gene introduced in the transgenic mice appeared not to include all the regulatory elements sufficient to exactly reflect all aspects of the spatio-temporal regulation of $B D N F$ gene expression. Such a difficulty observed in a transgenic model for human apolipoprotein B was circumvented by using large (145 and $207 \mathrm{~kb}$ ) bacterial artificial chromosomes as transgenes (Nielsen et al., 1997). Yeast artificial chromosomes (YAC) can also be used as transgenes. YACs were initially designed for positional cloning (Burke et al, 1987). These vectors allow the construction of transgenes carrying very large 5 ' and 3 ' flanking regions, as well as introns, which are sometimes required to faithfully reproduce native gene expression. Accuracy of human gene expression in a mouse transgenic context has been reported in various examples (Lamb et al, 1995, Huxley, 1998, Stocksley et al, 2005). Complementation of murine genetic defects through insertion of a YAC or a BAC containing the native human homologous gene (Hodgson et al, 1996, Schedl et al, 1996, Manson et al, 1997, Sarsero et al, 2004) also indicates appropriate regulation of human genes in such transgenic mouse models.

In order to contribute to the definition of new therapeutical strategies based on the regulation of human BDNF gene expression, we have decided to study its expression using a YAC-transgenic model. Our approach consisted in generating transgenic mice with a 145-kb YAC including the complete human BDNF gene, surrounded by large genomic sequences likely to contain most regulatory signals, and in which the coding sequence of the gene was replaced by the E-GFP (enhanced green fluorescent protein) reporter gene (Cormack et al, 1996). Several transgenic mouse models have documented the interest of using such a reporter gene which can be readily detected by fluorescent microscopy (Ikawa et al, 1995, Zhuo et al, 1997, Godwin et al, 1998, van den Pol et al, 1998).

Five transgenic mice harboring the engineered 145-kb YAC were obtained by pronuclear microinjection in mouse oocytes and lines were established by breeding. The expression pattern of the 
different transgenic transcripts was then analyzed in mouse heart and brain by RT-PCR and in situ detection of E-GFP fluorescence was performed on brain sections. These experiments reveal that one of the transgenic line displays a BDNF-specific pattern of transgene expression in the brain. This transgenic line constitutes the expected animal model for exploring potential pharmacological modulators of human $B D N F$ gene expression. 


\section{MATERIALS AND METHODS}

\section{Materials}

The 145-kb YAC containing the human BDNF gene used to create the transgene was obtained by fragmentation of the 810-kb mega YAC $886 \mathrm{H} 12$ (CEPH-Fondation Jean Dausset, Paris) as described previously (Guillemot et al, 1999). Oligonucleotides (Table 1 ; (Rosier et al, 1994, Guillemot et al, 1999)) were purchased from Life Technologies or Genosys. Mice were provided by IFFA-CREDO. Restriction endonucleases were purchased from New England Biolabs.

\section{Retrofitting of the YAC containing the human BDNF gene}

The reporter gene encoding the Enhanced Green Fluorescent Protein (E-GFP) (Cormack et al, 1996) was inserted into the 145-kb fragmented YAC using the two-step modification method called " popin, pop-out ", as previously described (Duff et al, 1994). The pEGBDPOP12 plasmid was designed for this purpose. It was created by cloning the reporter gene sequence, surrounded by two portions of the human BDNF gene coding exon, into the HindIII cloning site of the pRS406 vector (Stratagene). A first version was constructed with the GFP wild-type gene cloned into the pCX-GFP plasmid, a kind gift from M. Okabe (Ikawa et al, 1995), using fusion PCR (Uchida, 1992). On one hand, an amplified segment flanking the 5' end of the human BDNF coding sequence (position 291 to 668 in Genbank M61181 sequence) was fused to a 717-bp GFP amplification product from the pCX-GFP plasmid; on the other hand the same GFP amplification product was fused to an amplified segment overlapping the 3' end of the human BDNF coding sequence (position 1207 to 1605). Chimeric fusion primers were designed so as to contain a Sphl site at each junction between the GFP and the BDNF sequences. After sequence checking, the two fusion products were cloned separately into PCR2.1 (Invitrogen) and combined through a common and unique Ndel site in the GFP sequence. The insert was then transfered into the pRS406 vector, yielding the pRS406-BDGFP plasmid. The GFP wild-type sequence was excised by Sphl digestion and replaced by the E-GFP sequence isolated from the pEGFP-N1 vector (Clontech, Genbank accession number : U55762). The 783-bp HindIII / Notl fragment containing the E-GFP coding sequence was ligated into the Sph/ site of the pRS406-BDGFP plasmid with appropriate adaptors, yielding the pEGBDPOP12 plasmid. For the "pop- 
in, pop-out" procedure, this plasmid was linearized by digestion with Bglll (position 418 in Genbank M61181 sequence) and purified prior to transformation into the YAC-containing yeast strain using a lithium acetate transformation procedure (Alkali Cation Transformation kit, BIO 101) according to the manufacturer's recommendations. Proper integration and excision of the URA3 vector sequences were selected on appropriate media and checked on several YAC clones by PCR as described elsewere (Duff et al, 1994). The expected modification was assessed by Southern blot analysis of Notl- and BssHIIdigested YAC DNA by pulsed-field gel electrophoresis (Guillemot et al, 1999).

\section{Generation of transgenic mice}

The 145-kb transgene was isolated by preparative pulsed-field gel electrophoresis and prepared for microinjection as described (Huxley, 1998). After concentration and dialysis, a $2 \mathrm{ng} / \mu \mathrm{l}$ YAC DNA solution was obtained. Transgenic mice were generated by pronuclear microinjection as described (Hogan et al, 1994). Eggs were derived from (C57BL/6J x DBA2) females mated to identical hybrid males. Founder mice were identified by PCR analysis with DNA prepared from tail biopsies, using the EGFPS and the EGFPAS primers (Table 1).

\section{Copy number estimation}

Southern blot was performed using $10 \mu \mathrm{g}$ of mouse genomic DNA extracted from tails and digested to completion with Banll (Biolabs). A 886-bp Banll fragment containing the E-GFP sequences was excised from the pEGBDPOP12 plasmid and used as template $(50 \mathrm{ng})$ to synthesize an $\left[\alpha-{ }^{32} \mathrm{P}\right] \mathrm{dCTP}$ labelled probe with the Random Priming Kit system (Life Technologies). Blots were hybridized for $1 \mathrm{~h}$ at $68^{\circ} \mathrm{C}$ in HybridExpress buffer (Clontech), washed following the manufacturer's recommendations and exposed on phosphor screens (Molecular Dynamics). The signals were imaged and quantitated with a Phosphorimager (Molecular Dynamics).

\section{RNA analysis}

Up to $250 \mathrm{mg}$ of tissues (brain or heart) were snap frozen in liquid nitrogen for storage at $-80^{\circ} \mathrm{C}$ or in the RNAlater solution (Ambion) for storage at $-20^{\circ} \mathrm{C}$. Poly(A) RNA was extracted using the MPG Direct mRNA purification kit (Quantum/Bioprobe) according to the manufacturer's protocol. A quantity of 250 to $500 \mathrm{ng}$ of poly(A) RNA was mixed with the same amount of oligodT $\mathrm{T}_{(12-18)}$ primer (Life Technologies) and 
used for cDNA synthesis using the Superscript II reverse transcriptase system (Life Technologies) as described previously (Guillemot et al, 1999). For the negative control, the same amount of RNA was submitted to similar incubation conditions except for the addition of reverse transcriptase. The cDNA corresponding to $12.5 \mathrm{ng}$ of poly(A) RNA was used as template for PCR amplification in a $35 \mu \mathrm{l}$ reaction volume. Amplification reactions were performed with specific primer sets (see Table 1) in 1X PCR buffer (Platinum, Life Technologies) supplemented with $1 \mathrm{mM} \mathrm{MgCl}_{2}, 0.2 \mathrm{mM} \mathrm{dNTPs}, 1 \mu \mathrm{M}$ of each primer and $0.25 \mathrm{U}$ of the antibody-complexed Platinum Taq DNA polymerase (Life Technologies). Cycling was as follows : 2 min at $94{ }^{\circ} \mathrm{C}, 39$ cycles (27 cycles for cyclophilin primers) composed of $30 \mathrm{sec}$ at $94^{\circ} \mathrm{C}, 30 \mathrm{sec}$ at $59^{\circ} \mathrm{C}$ and $30 \mathrm{sec}$ at $72^{\circ} \mathrm{C}$, and $8 \mathrm{~min}$ at $72^{\circ} \mathrm{C}$.

\section{E-GFP imaging in vibratome sections}

Hemizygous transgenic or control adult mice were perfused with $4 \%$ paraformaldehyde in $0.1 \mathrm{M}$ PBS ( $\mathrm{pH}$ 7.4). Brains were removed and post-fixed in the same fixative for an additional $48 \mathrm{~h}$ at $4^{\circ} \mathrm{C}$, rinsed twice in $0.1 \mathrm{M}$ PBS, embedded in $4 \%$ low melting point agarose and cut on a Leica vibratome at a thickness of $70 \mu \mathrm{m}$ in the coronal plane. Sections were mounted in Fluoromount (Cliniscience) and E-GFP fluorescence was visualized with a fluorescence DRMB microscope (Leica) or with a fluorescence stereomicroscope MZ FLIII (Leica) combined with a cooled digital camera ORCA-100 (Hamamatsu Photonics).

\section{PCR reactions}

Mouse tail DNA lysate was prepared as follows : a piece of tail was incubated in $500 \mu$ l of lysis buffer (50 mM Tris-HCl pH 8; $100 \mathrm{mM} \mathrm{NaCl}$; $0.5 \%$ Tween 20) supplemented with $600 \mu \mathrm{g}$ of proteinase $\mathrm{K}$ (Boehringer), at $55^{\circ} \mathrm{C}$ overnight. The lysate was then centrifuged and $1 \mu \mathrm{l}$ of the supernatant was used as template in a $25 \mu \mathrm{l}$ PCR reaction volume using the Ready-To-Go kit (Pharmacia Biotech) in the presence of the EGFPS and EGFPAS primers ( $1 \mu \mathrm{M}$ of each). Cycling conditions were as follow : $1 \mathrm{~min}$ at $94^{\circ} \mathrm{C}, 29$ cycles composed of $1 \mathrm{~min}$ at $94^{\circ} \mathrm{C}, 1 \mathrm{~min}$ at $60^{\circ} \mathrm{C}, 1 \mathrm{~min}$ at $72^{\circ} \mathrm{C}$ and $10 \mathrm{~min}$ at $72^{\circ} \mathrm{C}$. Except for the annealing temperature (Table 1), the same cycling conditions were applied for amplification with the HIS3 primer set which corresponds to a portion of the YAC right arm. In this case, the reaction was performed with the BioTaq DNA polymerase (0.5 U, Eurobio) in the corresponding buffer supplemented with $1.5 \mathrm{mM}$ $\mathrm{MgCl}_{2}, 1 \mu \mathrm{M}$ of each primer and $0.2 \mathrm{mM}$ dNTPS. For the other YAC-specific STSs $(886 \mathrm{H} 12 \mathrm{~L}, \mathrm{~A} 2 \mathrm{C} 4$, 
B2F11, C2C4 and C2D9) which are described in Guillemot et al. (1999), amplifications were performed in the same reaction conditions but with another cycling program: 2 min at $94^{\circ} \mathrm{C}, 30$ cycles composed of 30 sec at $94^{\circ} \mathrm{C}, 30 \mathrm{sec}$ at $59^{\circ} \mathrm{C}, 30 \mathrm{sec}$ at $72^{\circ} \mathrm{C}$ and $8 \mathrm{~min}$ at $72^{\circ} \mathrm{C}$.

\section{RESULTS}

\section{Construction of the YAC transgene}

A 145-kb YAC derived from the CEPH 886H12 YAC (42) was modified to produce the transgene. This YAC (Figure 1A) carries the human BDNF gene spanning $67 \mathrm{~kb}$ (distance on the genome from the beginning of the most upstream 5' exon to the last nucleotide of the longest version of the coding exon), flanked by about $35 \mathrm{~kb}$ downstream of the coding exon and $45 \mathrm{~kb}$ upstream of 5 ' exons cluster 1 . Approximate mapping of the BDNF gene on the YAC results from both previous restriction map analysis (Rosier et al, 1994) and localisation of the Notl and BssHII sites between exon III and IV and close upstream of the coding exon respectively (Figure 1A). The genomic coordinates of the YAC insert on the human genome sequence (NCBI Build 35) can thus be approximated to chr11:27 600 000-27 745 000. A picture of the genomic context of the BDNF gene in this region can be obtained from the Genome Browser (http://genome-test.cse.ucsc.edu/cgi-bin/hgTracks) and is represented in Figure 1B. Several mRNAs corresponding to a poorly characterized gene transcribed from the opposite DNA strand overlap the coding region and last intron of the $B D N F$ gene. No promoter region other than the one corresponding to the $B D N F$ gene seems to be present in the YAC, as only two groups of $\mathrm{CpG}$ islands are nicely co-localized with the two clusters of $5^{\prime}$ exons of the BDNF gene. In addition to the BDNF gene, we have previously identified and mapped on this YAC the four sequence-tagged sites (STSs) C2D9, B2F11, C2C4 and A2C4, corresponding to human 3' terminal sequences (AJ011602, AJ011597, AJ011601, and AJ011593 respectively) isolated by an exon trapping procedure (Guillemot et al, 1999).

YAC modification consisted in the partial replacement of the coding exon of the BDNF gene by the reporter gene encoding the enhanced green fluorescent protein (E-GFP). Three bases downstream the translation initiator codon of the BDNF gene, a 540-bp exonic portion was replaced by a 783-bp plasmidic sequence containing the reporter gene (Figure 1A). The substitution was performed using a method based 
on homologous recombination called "pop-in, pop-out" (Duff et al, 1994), which required construction of a plasmid bearing the expected modification (see Materials and Methods). Expression of the reporter gene product from this construction was checked by subcloning the substituted BDNF coding exon into the pCDNA3 expression vector (Invitrogen) and observing fluorescence upon transfection into COS cells (not shown). The "pop-in, pop-out" procedure yielded a YAC clone harboring the expected features, that was characterized by PCR and Southern blot analysis. The E-GFP sequence was shown to be present in the 80-kb Notl fragment containing the coding exon of the BDNF gene and amplification experiments using primers specific for E-GFP and BDNF sequences confirmed that the replacement had been correctly done (data not shown). This resulting recombinant YAC, named 886EGFBD, was used as transgene.

\section{Generation of transgenic mice}

DNA from the recombinant 886EGFBD YAC was gel purified and microinjected into fertilized oocytes that were transplanted into foster mothers. From 320 injected eggs, 18 live born animals were obtained. Tail DNA from this progeny was screened using primers specific for the E-GFP reporter gene and five positive founder mice were identified. Transgenic lines were derived from the breeding of founders with non-transgenic C57BL/6J mice. To assess transgene integrity, mouse genomic DNA was also tested with six other PCR markers that span the entire length of the YAC (Figure 1A). All of them were detected in the genomic DNA of all founder animals and were transmitted to the offspring. Interestingly, in one of these lines (called EGFBD11) transgene transmission was restricted to males, suggesting integration in the murine $\mathrm{Y}$ chromosome.

As a first screening for accurate transgene expression, detection of transgenic transcripts containing BDNF exon cl1-2 was performed by RT-PCR using poly(A) RNA prepared from brain of mice from the five transgenic lines. BDNF exon II is known to be expressed specifically in brain. The expected transcript was detected only in three transgenic lines (named EGFBD3, EGFBD7 and EGFBD10) which were further analyzed. Southern blotting was performed to determine the number of transgene copies integrated in the genome of the transgenic mice (data not shown). The EGFBD3 mice integrated two or three copies of the YAC whereas a higher copy number was detected for the EGFBD7 and EGFBD10 lines (about 7 and 6 copies respectively). 


\section{Transcript analysis}

After testing the presence of the transgenic transcripts containing human BDNF exon cl1-2 in brain, RT-PCR assays were performed to detect the transgenic transcripts containing the three other $5^{\prime}$ exons (cl1-1, cl2-1 and cl2-2). For all lines analyzed, a signal can be detected for each type of transcript in brain (Figure 2A, left panels). This expression pattern reproduces the pattern of endogenous BDNF gene in this organ (Figure 2B, left panel). Interestingly, in addition to the 315-bp band expected for transgenic cl1-2 transcript, a smaller product was also produced upon amplification in the presence of exon-cl1-2 sense primer (Figure 2A, lanes cl1-2 +). This product was cloned and its sequence revealed that is corresponds to an alternative splicing form of exon-cl1-2 transcript in which $83 \mathrm{nt}$ are skipped at the 3' end of exon cl1-2. Indeed, the existence of three alternatively spliced exon-cl1-2 transcripts has recently been observed (Liu et al, 2005) upon sequencing of various BDNF isoform mRNAs and confirms our observation (isoforms 2A : AY054393, 2B : AY054394, and 2C : AY054395, this last one being truncated by $83 \mathrm{nt}$ to produce isoform 2B). A similar amplification product is visible upon amplification of mouse endogenous exon-cl1-2 transcript (Figure 2B, lane $\mathrm{cl} 1-2+$ ). Sequence comparison between the murine and human transgenic truncated products revealed that they correspond in both species to the usage of an alternative donor splice site located at the same position in exon cl1-2 (unpublished results). Here again, sequences available for BDNF exon-cl1-2 transcripts in mouse (Liu et al, 2006) confirm the existence of three isoforms very similar to the three isoforms observed in human.

In order to study the expression of the various transgenic transcripts in a non-neuronal tissue, RTPCR assays were then implemented with poly(A) RNA prepared from heart (Figure 2, right panels). It has been established previously that transcripts containing exons cl1-1 or cl1-2 of the rat BDNF gene are not expressed in heart whereas exon-cl2-1 and -cl2-2 promoters are active in this organ (Timmusk et al, 1995). Our results are in good agreement with this observation since no signal was detected in nontransgenic mouse heart for murine exon-cl1-1 and -cl1-2 transcripts, whereas murine exon-cl2-1 and -cl22 transcripts were shown to be expressed in heart (Figure 2B, lanes $\mathrm{cl} 1-1$ to $\mathrm{cl} 2-2$ ). Of the three transgenic lines analyzed, only line EGFBD10 displayed expression of transgenic exon-cl2-1 and $\quad-\mathrm{cl} 2-2$ transcripts in heart (Figure 2A, lanes $\mathrm{cl} 2-1$ and $\mathrm{cl} 2-2)$. Expression of murine exon-cl2-1 and -cl2-2 transcripts was 
found positive in all analyzed heart samples from EGFBD3, EGFBD7 and EGFBDD10 lines (data not shown). However the same heart RNA samples failed to give any signal for the corresponding transgenic transcripts in EGFBD3 and EGFBD7 lines.

In conclusion, a transgenic expression pattern concordant with that of the endogenous BDNF gene in mouse brain and heart was detected only in line EGFBD10.

\section{E-GFP detection in the brain}

In order to analyse transgene expression in situ, vibratome sections were performed on brain from transgenic and non transgenic adult mice and the slices were illuminated with appropriate UV light to visualize E-GFP fluorescence. Detection analysis was focused on coronal sections at the level of the hippocampal formation and the claustrum, two cerebral areas where the highest levels of reporter gene expression were expected. In brain sections from EGFBD3 and EGFBD7 mice, no specific E-GFP signal could be distinguished from the non-transgenic tissue autofluorescence (data not shown). By contrast, in the EGFBD10 line, cells showing strong E-GFP fluorescence were detected in the hippocampus and claustrum (Figure 3A, panels 2 and 4).

In the hippocampus (Figure 3A, panel 2), cells expressing E-GFP at high level were localized in the dentate gyrus and in the CA3 region of Amon's horn. Transgene expression was not detected in CA1. In Amon's horn, the E-GFP labeled cells were found in the pyramidal cell layer. In the dentate gyrus, transgene expression was detected in cells of the stratum granulosum, mainly localized close to the separation with the inner molecular layer (Figure 3B, panel 2). The neuronal nature of these labeled hippocampal cells was assessed by immunohistochemical detection of the neuron-specific marker MAP2 (data not shown). Intracellular distribution of E-GFP appeared rather homogenous and allowed to reveal the cellular morphology (cell bodies and neurites) of these labeled neurons (Figure 3B, panels 1 and 2). In the claustrum, high levels of E-GFP were also detected (Figure 3A panel 4) in clearly stained cell bodies.

In addition to the hippocampus and claustrum, E-GFP expression was also observed in the neocortex (Figure 3A, panels 2 and 4, arrows). Localization of the labeled neurons seemed to be restricted to an intermediate layer in the parietal cortex. Transgene expression was further analyzed on several 
sections throughout the brain and cerebellum of mice from the EGFBD10 line but these observations failed to reveal any additional structure producing detectable levels of E-GFP.

Taken together these results show that in the transgenic line EGFBD10, the human $B D N F$ promoter is able to drive specific expression of the E-GFP reporter gene and that the obtained pattern is restricted in brain to subsets of neurons from the hippocampus, claustrum and parietal part of the brain cortex.

\section{DISCUSSION}

The work reported here aimed at assembling together various features to produce an appropriate model to study potential modulators of human BDNF gene expression in vivo. (i) The model is an animal model so as to gain access to all stages and places of expression of the gene. In addition, the transgenic mouse line thus obtained constitutes an available source of various cell types containing the same recombinant construction. (ii) The BDNF promoter considered is of human origin to increase the chance that the results of the study can be used for therapy of human diseases. This promoter is handled in a YAC to retain a large portion of the regulatory sequences around the human BDNF gene. (iii) A reporter-gene coding sequence has been inserted in the BDNF coding exon to trace the activity of the gene. This reporter coding sequence (about $780 \mathrm{bp}$ ) is similar in size to the replaced sequence of the $B D N F$ coding exon (540 bp). Thus this substitution does not alter the overall structure of the BDNF gene, and probably affects in a very limited way the structure of its mRNA. (iv) The reporter gene encodes E-GFP with fluorescent properties used in many living cells or organisms (Cubitt et al, 1995, Misteli et al, 1997), a feature which may allow straightforward development of novel detection systems and high-throughput screening procedures (Gervaix et al, 1997).

Microinjection of the 145-kb engineered YAC into fertilized mouse oocytes resulted in an efficiency of $27 \%(5 / 18)$ of transgenesis among all born animals. This is very similar to the efficiencies obtained with constructions of more limited size. The genome of the five transgenic lines obtained contained intact YAC 
DNA as shown by monitoring STS content, suggesting that few if any deletion occurred during transgenesis. As observed in other cases (Lamb et al, 1995), pronuclear microinjection proved to be a straightforward method to produce YAC transgenic mice. Despite the fact that the preparation and manipulation of high-molecular weight DNA prior to the microinjection are very demanding steps, this method has been used successfully for YAC DNA up to nearly $700 \mathrm{~kb}$ (Smith et al, 1995).

Three from the five transgenic lines obtained expressed the transgene in brain. This is less than expected when considering the large size of the transgene. Indeed, it is generally assumed, and it has been confirmed in many cases, that large DNA segments will contain the necessary signals, such as matrix attachments regions (MAR), to insulate active loops of chromatin and thus annihilate position effects in transgenic models (McKnight et al, 1992, Namciu et al, 1998). The MAR elements, ranging from 100 to $1000 \mathrm{bp}$, are estimated to be present in about 100,000 copies in mammalian genomes (Bode et al, 1996), i.e. one every $30 \mathrm{~kb}$ in the human genome if evenly spaced. Thus, the likelihood that one or more MAR exist in the inserted $145-\mathrm{kb}$ transgene is high. Nevertheless, the functions of MARs are very diverse and some cases have already been reported where insertion of a MAR element on both sides of a transgene is not sufficient to ensure position-independent and/or faithful tissue specific expression (Barash et al, 1996, Neznanov et al, 1996). In our study, persisting positional effects may also result from some as yet undescribed dominant effects of mouse MARs on one or both sides on the transgene.

Analysis of tissue-specific expression of the transgene revealed that two from the three lines expressing the transgene in brain did not express the transgenic exon-cl2-1 and -cl2-2 transcripts in heart. This defect in the pattern of expression is likely correlated to the lack of detection of the reporter gene product in situ for these two lines. Indeed, although the presence of a transcript was clearly established by RT-PCR performed on total brain mRNA (figure 2A, left panels), it was impossible to detect any welldefined regions of fluorescence in the brain of these transgenic animals, in particular in the hippocampus known as the main site for BDNF gene expression. Transcription levels may be insufficient and/or presenting a too diffuse distribution in brain to produce enough E-GFP for detection. The use of improved detection techniques allowing to increase the ratio between specific E-GFP signals and background autofluorescence should help testing this hypothesis. Putative position effects are likely responsible for this situation and could be investigated using larger $(>145 \mathrm{~kb})$ transgene constructs. Indeed, the large size of 
the BDNF gene itself $(\sim 67 \mathrm{~kb})$ and its position in the YAC utilized here are limiting the length of available regulatory regions on each side of the gene (45 and $35 \mathrm{~kb}$ upstream and downstream respectively). Longer YACs extending further upstream the transgene have been produced through fragmentation of the 810-kb initial YAC (Guillemot et al, 1999) and could be used in future experiments to increase the chance to get position-independent expression and appropriate tissue distribution of the transcript.

Finally, in situ detection of the fluorescent reporter gene product was successful for one of the transgenic line. In this line, the restricted pattern of expression observed in the hippocampus, claustrum and cortex is very consistent with previous reports in rat brain (Yan et al, 1997, Conner et al, 1997). In primate, hippocampus is found as the major site of detection of BDNF mRNA (Phillips et al, 1991, Murray et al, 1994) and protein (Hayashi et al, 1997, Murer et al, 1999). Our transgenic model allows easy in situ visualization of the human $B D N F$ gene activity and may thus become a valuable tool to further investigate the human $B D N F$ gene regulation in vivo.

A YAC-transgenic mouse line correctly expressing E-GFP protein under the control of the human $B D N F$ gene is now available. Further characterization should lead to develop a high throughput screening assay for pharmacological substances capable of modulating BDNF gene expression in vivo. Proper regulation of the gene can first be checked using various neurotransmitters analogs and hormones already known as potent stimulators of BDNF transcription in vivo such as agonists for NMDA-glutamate (da Penha Berzaghi et al, 1993), cholinergic muscarinic and serotonin $5 \mathrm{HT}_{2 \mathrm{~A} / 2 \mathrm{C}}$ receptors (Vaidya et al, 1997), antagonists for $\mathrm{GABA}_{\mathrm{A}}$ receptors (Metsis et al, 1993), estradiol (Singh et al, 1995) and AVP(4-8) peptide (Zhou et al, 1997). Cell culture systems can then be established from the transgenic animals, in which activity of the BDNF promoter could be monitored by fluorescence measurement of the reporter gene product following application of series of pharmacological substances. The identified active compounds would then undergo whole animal assays to check for in vivo efficiency and absence of secondary effects. The therapeutic value of such compounds could then be tested in animal models of neurodegenerative diseases prior to entering clinical trials with human patients. In conclusion, the availability of a transgenic mouse model in which faithful brain-specific expression of a human BDNF-GFP transgene is achieved 
opens a large field of potential discoveries which may lead to innovative strategies for the treatment of neurodegenerative diseases.

\section{ACKNOWLEDGEMENTS}

We wish to thank Esther Toselli and Cécile Hervieux for DNA sequencing, Arlette Loeuillet, René Papion-Duchateau, Jean-Paul Moussu and Patrice Medina from SEAT for technical assistance in trangenesis and mouse manipulation, Nathalie Spassky and Bernard Zalc (INSERM U-495, Hopital de la Salpétrière, Paris) for help in E-GFP visualization, MAP2 detection and interest for this work. We are indebtful to Clare Huxley for advices and sharing protocols. This work was supported by grants from Association Française contre les Myopathies (AFM) and Ligue Nationale contre le Cancer. The authors are grateful to Association France-Alzheimer for interest and financial support provided to FG. FG also benefited from fellowships from AFM, Ligue Nationale contre le Cancer, Association pour la Recherche contre le Cancer and from Cold Spring Harbor Laboratory concerning the "YACs in Structural \& Biological Genome Analysis" course.

\section{REFERENCES}

Levi-Montalcini R (1987) The nerve growth factor: thirty-five years later. Embo J 6:1145-1154

Hallbook F, Lundin LG and Kullander K (1998) Lampetra fluviatilis neurotrophin homolog, descendant of a neurotrophin ancestor, discloses the early molecular evolution of neurotrophins in the vertebrate subphylum. J Neurosci 18:8700-8711

Snider WD (1994) Functions of the neurotrophins during nervous system development: what the knockouts are teaching us. Cell 77:627-638

Davies AM and Wright EM (1995) Neurotrophic factors. Neurotrophin autocrine loops. Curr Biol 5:723-726

Connor B and Dragunow M (1998) The role of neuronal growth factors in neurodegenerative disorders of the human brain. Brain Res Brain Res Rev 27:1-39

Yuen EC and Mobley WC (1996) Therapeutic potential of neurotrophic factors for neurological disorders. Ann Neurol 40:346-354 
Ferrer I, Goutan E, Marin C et al (2000) Brain-derived neurotrophic factor in Huntington disease. Brain Res 866:257-261

Phillips HS, Hains JM, Armanini M et al (1991) BDNF mRNA is decreased in the hippocampus of individuals with Alzheimer's disease. Neuron 7:695-702

Murray KD, Gall CM, Jones EG et al (1994) Differential regulation of brain-derived neurotrophic factor and type II calcium/calmodulin-dependent protein kinase messenger RNA expression in Alzheimer's disease. Neuroscience 60:37-48

Nonomura T, Nishio C, Lindsay RM et al (1995) Cultured basal forebrain cholinergic neurons from postnatal rats show both overlapping and non-overlapping responses to the neurotrophins. Brain Res 683:129-139

Eide FF, Lowenstein DH and Reichardt LF (1993) Neurotrophins and their receptors--current concepts and implications for neurologic disease. Exp Neurol 121:200-214

McAllister AK, Katz LC and Lo DC (1999) Neurotrophins and synaptic plasticity. Annu Rev Neurosci 22:295-318

Mattson MP, Maudsley S and Martin B (2004) BDNF and 5-HT: a dynamic duo in age-related neuronal plasticity and neurodegenerative disorders. Trends Neurosci 27:589-594

Patterson SL, Abel T, Deuel TA et al (1996) Recombinant BDNF rescues deficits in basal synaptic transmission and hippocampal LTP in BDNF knockout mice. Neuron 16:1137-1145

Ma YL, Wang HL, Wu HC et al (1998) Brain-derived neurotrophic factor antisense oligonucleotide impairs memory retention and inhibits long-term potentiation in rats. Neuroscience 82:957-967

Knusel B and Gao H (1996) Neurotrophins and Alzheimer's disease: beyond the cholinergic neurons. Life Sci 58:2019-2027

Wu D and Pardridge WM (1999) Neuroprotection with noninvasive neurotrophin delivery to the brain. Proc Natl Acad Sci U S A 96:254-259

Gimenez y Ribotta M, Revah F, Pradier L et al (1997) Prevention of motoneuron death by adenovirusmediated neurotrophic factors. J Neurosci Res 48:281-285

Menei P, Montero-Menei C, Whittemore SR et al (1998) Schwann cells genetically modified to secrete human BDNF promote enhanced axonal regrowth across transected adult rat spinal cord. Eur J Neurosci 10:607-621

Martinez-Serrano A, Hantzopoulos PA and Bjorklund A (1996) Ex vivo gene transfer of brain-derived neurotrophic factor to the intact rat forebrain: neurotrophic effects on cholinergic neurons. Eur J Neurosci 8:727-735

Levivier M, Przedborski S, Bencsics C et al (1995) Intrastriatal implantation of fibroblasts genetically engineered to produce brain-derived neurotrophic factor prevents degeneration of dopaminergic neurons in a rat model of Parkinson's disease. J Neurosci 15:7810-7820 
Girard C, Bemelmans AP, Dufour N et al (2005) Grafts of brain-derived neurotrophic factor and neurotrophin 3-transduced primate Schwann cells lead to functional recovery of the demyelinated mouse spinal cord. J Neurosci 25:7924-7933

Saporito MS, Wilcox HM, Hartpence KC et al (1993) Pharmacological induction of nerve growth factor mRNA in adult rat brain. Exp Neurol 123:295-302

Carswell S (1993) The potential for treating neurodegenerative disorders with NGF-inducing compounds. Exp Neurol 124:36-42

Semkova I and Krieglstein J (1999) Neuroprotection mediated via neurotrophic factors and induction of neurotrophic factors. Brain Res Brain Res Rev 30:176-188

Timmusk T, Palm K, Metsis M et al (1993) Multiple promoters direct tissue-specific expression of the rat BDNF gene. Neuron 10:475-489

Bishop JF, Mueller GP and Mouradian MM (1994) Alternate 5' exons in the rat brain-derived neurotrophic factor gene: differential patterns of expression across brain regions. Brain Res Mol Brain Res 26:225-232

Hayes VY, Towner MD and Isackson PJ (1997) Organization, sequence and functional analysis of a mouse BDNF promoter. Brain Res Mol Brain Res 45:189-198

Rosier MF, Goguel AF, Martin A et al (1994) A 1.7-Mb YAC contig around the human BDNF gene (11p13): integration of the physical, genetic, and cytogenetic maps in relation to WAGR syndrome. Genomics 24:69-77

Timmusk T, Lendahl U, Funakoshi $\mathrm{H}$ et al (1995) Identification of brain-derived neurotrophic factor promoter regions mediating tissue-specific, axotomy-, and neuronal activity-induced expression in transgenic mice. J Cell Biol 128:185-199

Hofer M, Pagliusi SR, Hohn A et al (1990) Regional distribution of brain-derived neurotrophic factor mRNA in the adult mouse brain. Embo J 9:2459-2464

Yan Q, Rosenfeld RD, Matheson CR et al (1997) Expression of brain-derived neurotrophic factor protein in the adult rat central nervous system. Neuroscience 78:431-448

Conner JM, Lauterborn JC, Yan Q et al (1997) Distribution of brain-derived neurotrophic factor (BDNF) protein and mRNA in the normal adult rat CNS: evidence for anterograde axonal transport. J Neurosci $17: 2295-2313$

Burke DT, Carle GF and Olson MV (1987) Cloning of large segments of exogenous DNA into yeast by means of artificial chromosome vectors. Science 236:806-812

Lamb BT and Gearhart JD (1995) YAC transgenics and the study of genetics and human disease. Curr Opin Genet Dev 5:342-348

Huxley C (1998) Exploring gene function: use of yeast artificial chromosome transgenesis. Methods $14: 199-210$

Stocksley MA, Chakkalakal JV, Bradford A et al (2005) A $1.3 \mathrm{~kb}$ promoter fragment confers spatial and temporal expression of utrophin A mRNA in mouse skeletal muscle fibers. Neuromuscul Disord 15:437449 
Hodgson JG, Smith DJ, McCutcheon K et al (1996) Human huntingtin derived from YAC transgenes compensates for loss of murine huntingtin by rescue of the embryonic lethal phenotype. Hum Mol Genet 5:1875-1885

Schedl A, Ross A, Lee M et al (1996) Influence of PAX6 gene dosage on development: overexpression causes severe eye abnormalities. Cell 86:71-82

Manson AL, Trezise AE, MacVinish LJ et al (1997) Complementation of null CF mice with a human CFTR YAC transgene. Embo J 16:4238-4249

Sarsero JP, Li L, Holloway TP et al (2004) Human BAC-mediated rescue of the Friedreich ataxia knockout mutation in transgenic mice. Mamm Genome 15:370-382

Cormack BP, Valdivia RH and Falkow S (1996) FACS-optimized mutants of the green fluorescent protein (GFP). Gene 173:33-38

Ikawa M, Kominami K, Yoshimura $Y$ et al (1995) A rapid and non-invasive selection of transgenic embryos before implantation using green fluorescent protein (GFP). FEBS Lett 375:125-128

Zhuo L, Sun B, Zhang CL et al (1997) Live astrocytes visualized by green fluorescent protein in transgenic mice. Dev Biol 187:36-42

Godwin AR, Stadler HS, Nakamura K et al (1998) Detection of targeted GFP-Hox gene fusions during mouse embryogenesis. Proc Natl Acad Sci U S A 95:13042-13047

van den Pol AN and Ghosh PK (1998) Selective neuronal expression of green fluorescent protein with cytomegalovirus promoter reveals entire neuronal arbor in transgenic mice. J Neurosci 18:10640-10651

Guillemot F, Auffray C and Devignes MD (1999) Detailed transcript map of a 810-kb region at 11p14 involving identification of 10 novel human 3' exons. Eur J Hum Genet 7:487-495

Duff K, McGuigan A, Huxley C et al (1994) Insertion of a pathogenic mutation into a yeast artificial chromosome containing the human amyloid precursor protein gene. Gene Ther 1:70-75

Uchida K (1992) Recombination and amplification of multiple portions of genomic DNA by a modified polymerase chain reaction. Anal Biochem 202:159-161

Hogan B, Beddington R, Costantini F et al (1994) Manipulating the Mouse Embryo In:Cold Spring Harbor Laboratory Press NY (ed)

Liu QR, Walther D, Drgon T et al (2005) Human brain derived neurotrophic factor (BDNF) genes, splicing patterns, and assessments of associations with substance abuse and Parkinson's Disease. Am J Med Genet B Neuropsychiatr Genet 134:93-103

Liu QR, Lu L, Zhu XG et al (2006) Rodent BDNF genes, novel promoters, novel splice variants, and regulation by cocaine. Brain Res 1067:1-12

Cubitt AB, Heim R, Adams SR et al (1995) Understanding, improving and using green fluorescent proteins. Trends Biochem Sci 20:448-455

Misteli T and Spector DL (1997) Applications of the green fluorescent protein in cell biology and biotechnology. Nat Biotechnol 15:961-964 
Gervaix A, West D, Leoni LM et al (1997) A new reporter cell line to monitor HIV infection and drug susceptibility in vitro. Proc Natl Acad Sci U S A 94:4653-4658

Smith DJ, Zhu Y, Zhang J et al (1995) Construction of a panel of transgenic mice containing a contiguous 2-Mb set of YAC/P1 clones from human chromosome 21q22.2. Genomics 27:425-434

McKnight RA, Shamay A, Sankaran L et al (1992) Matrix-attachment regions can impart positionindependent regulation of a tissue-specific gene in transgenic mice. Proc Natl Acad Sci U S A 89:69436947

Namciu SJ, Blochlinger KB and Fournier RE (1998) Human matrix attachment regions insulate transgene expression from chromosomal position effects in Drosophila melanogaster. Mol Cell Biol 18:2382-2391

Bode J, Stengert-lber M, Kay V et al (1996) Scaffold/matrix-attached regions: topological switches with multiple regulatory functions. Crit Rev Eukaryot Gene Expr 6:115-138

Barash I, Ilan N, Kari R et al (1996) Co-integration of beta-lactoglobulin/human serum albumin hybrid genes with the entire beta-lactoglobulin gene or the matrix attachment region element: repression of human serum albumin and beta-lactoglobulin expression in the mammary gland and dual regulation of the transgenes. Mol Reprod Dev 45:421-430

Neznanov N, Kohwi-Shigematsu T and Oshima RG (1996) Contrasting effects of the SATB1 core nuclear matrix attachment region and flanking sequences of the keratin 18 gene in transgenic mice. Mol Biol Cell $7: 541-552$

Hayashi M, Yamashita A and Shimizu K (1997) Somatostatin and brain-derived neurotrophic factor mRNA expression in the primate brain: decreased levels of mRNAs during aging. Brain Res 749:283-289

Murer MG, Boissiere F, Yan Q et al (1999) An immunohistochemical study of the distribution of brainderived neurotrophic factor in the adult human brain, with particular reference to Alzheimer's disease. Neuroscience 88:1015-1032

da Penha Berzaghi M, Cooper J, Castren E et al (1993) Cholinergic regulation of brain-derived neurotrophic factor (BDNF) and nerve growth factor (NGF) but not neurotrophin-3 (NT-3) mRNA levels in the developing rat hippocampus. J Neurosci 13:3818-3826

Vaidya VA, Marek GJ, Aghajanian GK et al (1997) 5-HT2A receptor-mediated regulation of brain-derived neurotrophic factor mRNA in the hippocampus and the neocortex. J Neurosci 17:2785-2795

Metsis M, Timmusk T, Arenas E et al (1993) Differential usage of multiple brain-derived neurotrophic factor promoters in the rat brain following neuronal activation. Proc Natl Acad Sci U S A 90:8802-8806

Singh M, Meyer EM and Simpkins JW (1995) The effect of ovariectomy and estradiol replacement on brain-derived neurotrophic factor messenger ribonucleic acid expression in cortical and hippocampal brain regions of female Sprague-Dawley rats. Endocrinology 136:2320-2324

Zhou AW, Li WX, Guo J et al (1997) Facilitation of AVP(4-8) on gene expression of BDNF and NGF in rat brain. Peptides 18:1179-1187 


\section{LEGENDS TO THE FIGURES}

Figure 1 : A. Description of the YAC transgene. The exons of human BDNF gene (symbolized by shaded boxes) are localized on the 145-kb YAC. The two clusters of 5' exons are labeled as cl1 and cl2 respectively. Exons cl1-1, cl1-2, cl2-1, cl2-2, corresponding to rat exons I, II, III and IV and analysed in this study are identified. Rare cutter restriction sites are indicated (B : BssHII, N : Notl). The grey arrows and circle indicate respectively the arms and the centromere of the YAC vector. The relative positions of the seven STSs which were shown to be present in all transgenic lines are indicated with dark triangles below the YAC map. A magnification of the YAC area where the BDNF coding exon (shaded box) has been partially replaced by EGFP reporter gene (hatched box) is shown above the map. The numbers correspond to positions on the BDNF gene partial sequence from Genbank M61181entry. Translation initiation codons (ATG) of the BDNF and E-GFP sequences are indicated as well as termination codons (TAG and TAA respectively).

B. Genomic context. This picture was returned from the Genome Browser web server and corresponds to bases 27600000 to 27745000 from human chromosome 11, NCBI build 35, assembly April 2004.

Figure 2 : RT-PCR analysis of transgene expression in brain and heart of transgenic mice (A), and comparison with endogenous BDNF gene expression in non transgenic mice (B). RT-PCR experiments were performed in the presence $(+)$ or in the absence $(-)$ of reverse transcriptase. PolyA+ RNA was extracted from brain and heart of transgenic (EGFBD3, EGFBD7 and EGFBD10 lines, panel A) and non transgenic (panel B) mice. Sense primers specific for each $5^{\prime}$ exon of human and mouse BDNF genes were used together with an antisense primer specific of either E-GFP (EGFPAS2, panel A) or mouse BDNF coding exon (mBDcodAS, panel B). The sense primers were the same for human and mouse exons cl1-1, cl1-2 and cl2-1 (hBDNFIS, hBDNFIIS and hBNDFIIIBS respectively) but differed for exon cl2-2 because of too many mismatches between the human and mouse sequences (hBDNFIVS and rBDNFIVS for human and mouse exon cl2-2 respectively). See Table 1 for primer sequences and product sizes. Amplification with specific primers for the cyclophilin gene transcript (mCYCLOS and mCYCLOAS, 
Table 1) was performed as a positive control (cyclo) to check the amount of cDNA in the samples. $m$ is the $100 \mathrm{pb}$ ladder DNA size markers from Fermentas.

Figure 3 : E-GFP in situ detection in brain of EGFBD10 mice. Coronal sections through the hippocampus and the claustrum of non transgenic (non-tg : A, panels 1 and 3 ) and transgenic (tg : A, panels 2 and 4 and B, panels 1 and 2) mice were analyzed by fluorescence microscopy with filters designed for E-GFP detection (GFP3 filter set, Leica). Low-magnifications images (A) were obtained using a cooled digital camera fitted to a fluorescence stereomicroscope. Autofluorescence in the brain sections was similar in transgenic and non transgenic mice. Integration was used during image acquisition to optimize the detection of the E-GFP signal. High-magnification photomicrographs (B) were obtained by direct visualization under a fluorescence microscope. In the hippocampal structure (A, panel 2), a high EGFP expression is clearly detected in the CA3 region of Amon's horn and in the dentate gyrus (DG). At higher magnification, the E-GFP-labeled neurons are localized in the pyramidal cell layer of CA3 (B, panel 1). In the dentate gyrus (B, panel 2), the E-GFP is expressed in a population of neurons from the granular cell layer $(\mathrm{GrDG})$, close to the inner molecular layer (iml). The claustrum $(\mathrm{Cl})$ also contains cells expressing a high level of E-GFP (A, panel 4). In addition to these internal structures, E-GFP fluorescence was also detected in an intermediate layer of the parietal cortex (A panels 2 and 4 , arrows). 
Table 1. List of oligonucleotides used in this study.

\begin{tabular}{|c|c|c|c|}
\hline primer name & sequence $5^{\prime}-3^{\prime}$ & \multicolumn{2}{|c|}{ product size (bp) } \\
\hline \multicolumn{4}{|c|}{ transgene analysis } \\
\hline HIS3S* & GAT GAC AGA GCA GAA AGC CC & \multirow{2}{*}{\multicolumn{2}{|c|}{524}} \\
\hline HIS3AS* & GGA GGG TAA TTC TGC TAG CC & & \\
\hline EGFPS & TCG AAT TCT GCA GTC GAC GG & \multirow{2}{*}{\multicolumn{2}{|c|}{454}} \\
\hline EGFPAS & GTC CTC CTT GAA GTC GAT GC & & \\
\hline \multicolumn{4}{|c|}{ expression analysis } \\
\hline EGFPAS2 & ACT TGT GGC CGT TTA CGT CG & \multirow{2}{*}{\multicolumn{2}{|c|}{$\gamma^{2}$}} \\
\hline mBDcodAS & CCA GTG ATG TCG TCG TCA GAC & & \\
\hline hBDNFIS & GGA ACT TCT CAC ATG ATG ACT TCA AAC & 311 & 276 \\
\hline hBDNFIIS & TGA GCT CGC TGA AGT TGG CTT & 350 & 315 \\
\hline hBDNFIIIBS & TAC CGG GCA CCA AAG ACT CG & 347 & 317 \\
\hline rBDNFIVS & GCT TTG ATG AGA CCG GGT TC & 356 & - \\
\hline hBDNFIVS & GCT TTA ATG AGA CAC CCA CC & - & 313 \\
\hline mCYCLOS $^{\dagger}$ & CGA GCT CTG AGC ACT GGA GAG AAA & \multirow{2}{*}{\multicolumn{2}{|c|}{260}} \\
\hline mCYCLOAS $^{\dagger}$ & TCC AGC CAT TCA GTC TTG GCA GTG C & & \\
\hline
\end{tabular}

$\mathrm{S}$ : sense, AS : antisense; ${ }^{*}$ and ${ }^{\dagger}$ : the annealing temperature was $55^{\circ} \mathrm{C}$ and $60^{\circ} \mathrm{C}$ respectively, in contrast to $59^{\circ} \mathrm{C}$ for all other primers. 